\title{
Effects of prostaglandins on ovarian blood flow in the bitch
}

\author{
B. Varga and G. Folly \\ Institute of Experimental Medicine, Hungarian Academy of Sciences, \\ H-1450 Budapest, P.O. Box 67, Hungary
}

\begin{abstract}
Summary. Oestrous and anoestrous mongrel dogs were anaesthetized with chloraloseurethane. In one group, the ovaries were isolated in situ and the effects of a 15-min infusion of PGF- $2 \alpha$ or PGE-2 on perfusion pressure were measured. In the other group, heated thermocouples were introduced into the stroma of each ovary to measure the changes of local blood flow in response to PGF-2 $\alpha$ and PGE-2 infused into the ovarian bursa for $15 \mathrm{~min}$. Intra-arterial infusion of $25,50,100$ or $200 \mathrm{ng}$ PGF- $2 \alpha / \mathrm{kg} /$ min did not affect perfusion pressure; PGE-2 doses of $3 \cdot 1,6 \cdot 2,12 \cdot 5$ or $25 \mathrm{ng} / \mathrm{kg} / \mathrm{min}$ caused reductions in proportion to the dose. All doses of PGF- $2 \alpha(50.0,100$ or 200 $\mathrm{ng} / \mathrm{kg} / \mathrm{min})$ or PGE-2 $(25,50$ or $100 \mathrm{ng} / \mathrm{kg} / \mathrm{min})$ increased blood flow in the ovarian stroma in proportion to the dose when administered by infusion into the ovarian bursa. There were no differences in the results from oestrous and anoestrous dogs.

It is concluded that PGF-2 $\alpha$ changes intraovarian blood distribution without interfering with the total blood flow while PGE-2 increases both the total and local ovarian blood flow.
\end{abstract}

\section{Introduction}

The uterine luteolytic factor is assumed to be prostaglandin (PG) F-2 $\alpha$ (Pharriss, 1971; McCracken, 1971; McCracken et al., 1972; Horton \& Poyser, 1973) and its effect depends on an intact uteroovarian vascular system (Baird \& Land, 1973) for the veno-arterial transfer of the luteolytic factor to the ovaries (Hixon \& Hansel, 1974). The inhibitory effect of PGF-2 $\alpha$ on the progesterone secretion of the corpus luteum may be connected with the constriction of the ovarian blood vessels, thereby decreasing ovarian blood flow (Pharriss, 1971; McCracken, 1971). However, Baird (1974) reports that PGF-2 $\alpha$ reduces progesterone secretion in sheep but does not reduce ovarian blood flow. In pseudopregnant rabbits, PGF-2 $\alpha$ increased local blood flow in the stroma while that to the corpus luteum was reduced (Novy \& Cook, 1973; Janson, Albrecht \& Ahrén, 1975). In the bitch, PGF-2 $\alpha$ is known to reduce ovarian progesterone secretion (Jöchle, Tomlinson \& Anderson, 1973), but ovarian blood flow has not been determined.

We therefore studied the effects of PGF-2 $\alpha$ and PGE-2 on the vascular resistance and local blood flow of canine ovaries.

\section{Materials and Methods}

The 39 dogs used were mongrels weighing $10-20 \mathrm{~kg}$ and of unknown reproductive history. They were classed as being oestrous or anoestrous from examination of the external genitalia and the ovary. Anaesthesia was induced by chloralose and urethane $(0.075$ and $0.75 \mathrm{~g} / \mathrm{kg}$, respectively).

Measurement of vascular resistance. In 19 animals ( 2 oestrous) the ovaries were isolated in situ from the surrounding fat tissues and uterine horn. The arteries and veins were cannulated on both sides and both arteries were perfused with a constant volume of blood by means of a two-channel peristaltic pump from the left femoral artery. Each ovary was perfused with $3-5 \mathrm{ml}$ blood/min at a perfusion pressure to reach $100-120 \mathrm{mmHg}$. In the arterial cannula there were two side-arms. In one of these perfusion pressure was measured by a Statham's pressure transducer and recorded. Through the other, various doses of PGF-2 $\alpha$ and/or PGE-2 (Upjohn) were administered to the left or right ovary, by an infusion pump, in a random sequence in volumes of $\leqslant 0.1 \mathrm{ml} / \mathrm{min}$ for $15 \mathrm{~min}$. When the 
perfusion pressure had returned to the basal value, another PG dose was infused. Blood from the two ovarian veins was led into the right jugular vein, but during infusions this connection was interrupted to prevent the applied agents from getting into the systemic circulation. Blood coagulation was inhibited by heparin ( $200 \mathrm{i} . \mathrm{u} . / \mathrm{kg}$ : Richter). When necessary, blood loss was counteracted by blood from intact dogs.

Measurement of local blood flow. Flexible, heated thermocouples (Hensel \& Ruef, 1954) were introduced parallel to the longitudinal axis into the stroma of both ovaries in another 20 dogs ( 3 oestrous) so that the changes in local blood flow could be determined by application of heat-clearance principles (McCaffrey \& McCook, 1975). The changes were expressed as a percentage of the resting value $(100 \%$ ). Blood pressure was measured in the femoral artery by a Statham's pressure transducer. Because PGs are known to be effective in the systemic circulation, they had to be applied locally. Direct administration into the ovarian artery was not feasible because of the resulting damage of the vascular wall. The introduction of a cannula into the blood vessel, however, necessitates pretreatment with heparin, which, in turn, might lead to the development of a haematoma around the thermocouple. Therefore, PGF-2 $\alpha$ and PGE-2 were administered through a thin cannula built into the ovarian bursa in volumes of $0.1 \mathrm{ml} / \mathrm{min}$ over $15 \mathrm{~min}$. PGs were administered into the left or right ovarian bursa once only. Preliminary experiments, in which the effects of administration of PGE-2 by intra-arterial injection and by way of the bursa were compared, showed that absorption by the latter route was satisfactory.

Statistical analysis. Changes occurring in a definite time were calculated and compared to the control level by analysis of variance and Student's $t$ test.

\section{Results}

The application of PGE-2 into one isolated ovary caused a reduction in the perfusion pressure and thus induced vasodilatation while PGF- $2 \alpha$ had no effect on the contralateral ovary (Text-fig. 1). Overall, none of the PGF-2 $\alpha$ doses had an effect on perfusion pressure but the response to PGE-2 was proportional to the dose given (Table 1).
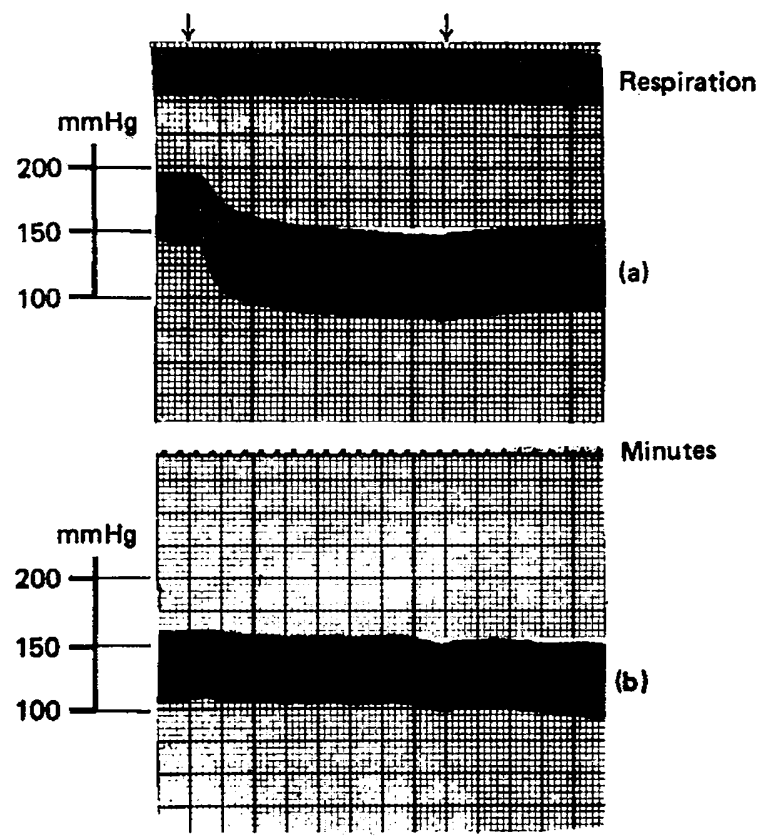

Text-fig. 1. A typical result to show the effect of prostaglandins on perfusion pressure for bitch ovaries isolated in situ. (a) Left ovary, $12.5 \mathrm{ng}$ PGE-2 $/ \mathrm{kg} / \mathrm{min}$, (b) right ovary, $200 \mathrm{ng}$ PGF-2 $\alpha / \mathrm{kg} / \mathrm{min}$ (arrows). 


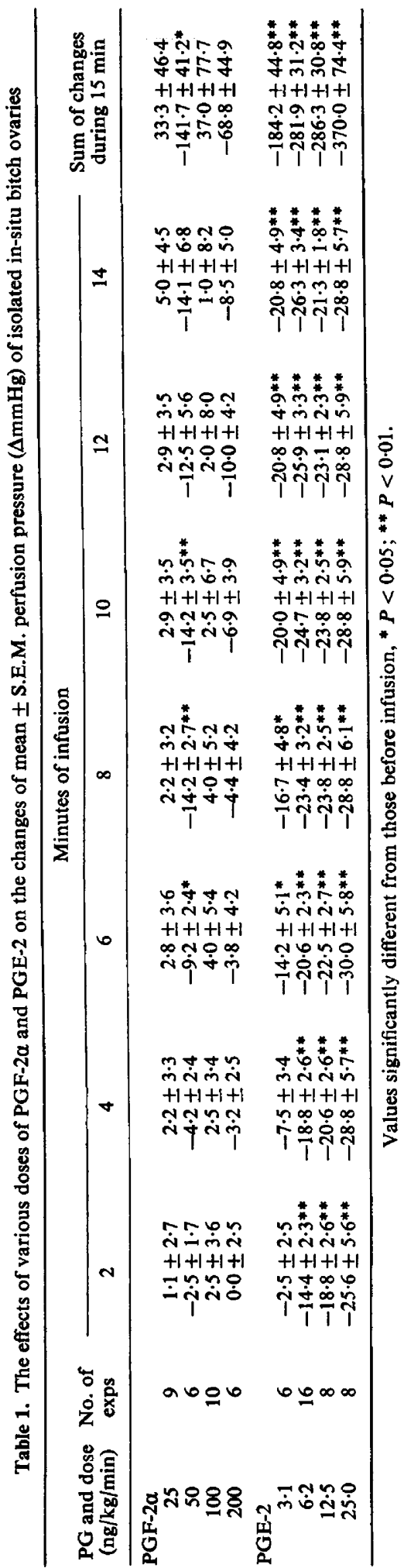

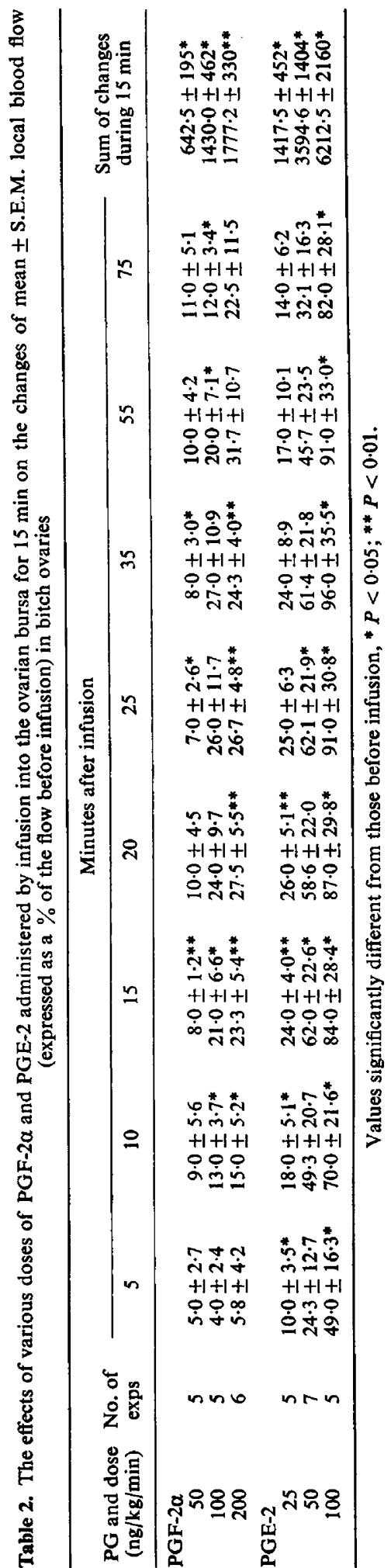

Downloaded from Bioscientifica.com at 04/26/2023 11:31:54AM 


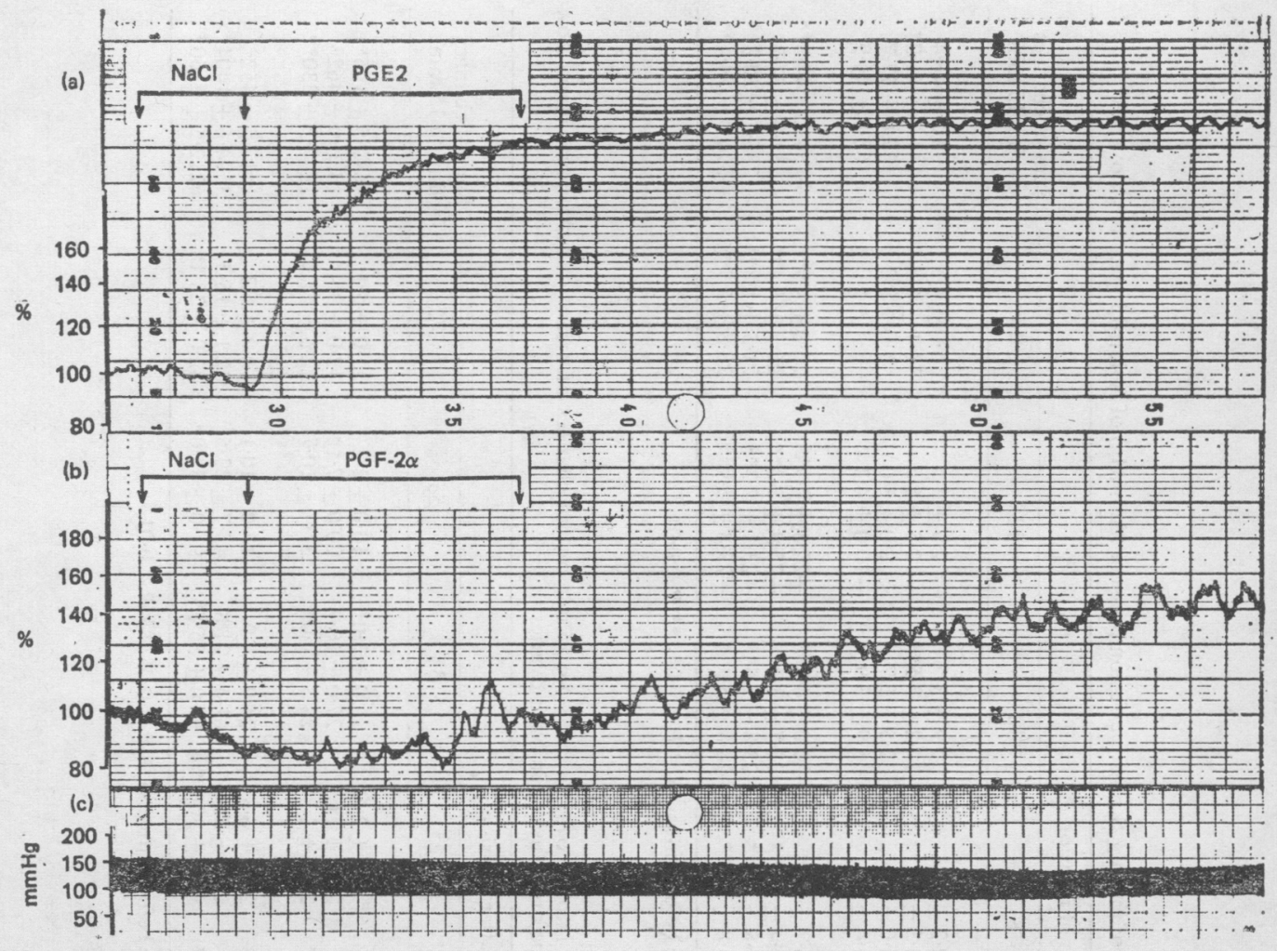

Text-fig. 2. A typical result to show the effect of prostaglandins administered by infusion into the ovarian bursa on the stromal blood flow of the bitch ovary. (a) Left ovary, $0.9 \% \mathrm{NaCl}$ at a rate $00.05 \mathrm{ml} / \mathrm{min}$ followed by $0.1 \mu \mathrm{g}$ PGE-2/kg/min; (b) right ovary, $0.9 \% \mathrm{NaCl}$ at a rate of $0.05 \mathrm{ml} / \mathrm{min}$ followed by $0.2 \mu \mathrm{g} \mathrm{PGF-}$ $2 \alpha / \mathrm{kg} / \mathrm{min}$; (c) blood pressure. The vertical divisions in (a) and (b) represent 2-min periods; time in (c) is synchronous.

The administration of the PGs via the ovarian bursa caused an appreciable augmentation of blood flow in the ovarian stroma (Text-fig. 2) which was related to the dose given (Table 2). PGE-2 was more effective than PGF-2 $\alpha$. No differences were found between the oestrous and anoestrous dogs in either of the experimental groups.

\section{Discussion}

Our results suggest that PGF-2 $\alpha$ increases blood flow in the ovarian stroma in the dog while the vascular resistance (total ovarian blood flow) of the organ remains unchanged. In dogs arteriovenous anastomoses can be observed in the hilum and in the stroma (B. Varga \& G. Ungváry, unpublished) and the changes in blood flow are probably due to differential closing and opening of the shunts.

The canine utero-ovarian vascular arrangements would permit the existence of a countercurrent mechanism for transfer of the luteolytic factor (McCracken, 1971) and PGF-2 $\alpha$ could be the luteolytic factor in the dog as it is in the sheep (McCracken et al., 1972) and guinea-pig (Horton \& Poyser, 1973), but it does not elicit vasoconstriction.

PGE-2 is synthesized in rabbit and rat ovaries after gonadotrophin stimulation (LeMaire, Yang, Behram \& Marsh, 1973; Bauminger \& Lindner, 1975). In the dog, ACTH increases ovarian blood flow (Stark, Varga \& Ács, 1967; Stark \& Varga, 1968). This effect can be blocked by indomethacin, a specific PG-inhibitor, and PGE-2 appears to be the mediator in the blood flow stimulatory effect 
of ACTH (Stark \& Varga, 1975). Our results suggest that PGE-2 may play a role in the regulation of total and local blood flow of the ovaries, while PGF-2 $\alpha$, whether originating from the uterus or formed in the ovary, may influence the redistribution of intraovarian blood flow.

Thanks are due Miss Susanna Kiss and Mr J. Horváth for their excellent technical assistance, and to Dr J. H. Pike, Upjohn Ltd, for the gifts of prostaglandins.

\section{References}

Baird, D.T. (1974) Prostaglandins $F_{2 \alpha}$ and ovarian blood flow in sheep. J. Endocr. 62, 413-414.

BAIRD, D.T. \& LAND, R.B. (1973) Division of the uterine vein and the function of the adjacent ovary in the ewe. J. Reprod. Fert. 33, 393-397.

Bauminger, S. \& Lindner, H.R. (1975) Preovulatory changes in ovarian prostaglandin formation and their hormonal control in the rat. Prostaglandins 9 , 737-751.

Hensel, H. \& Ruef, J. (1954) Fortlaufende Registrierung der Muskeldurchblutung am Menschen mit einer Calorimetersonde. Pfügers Arch. 254, 267-280.

Hixon, J.W. \& Hansel, W. (1974) Evidence for preferential transfer of prostaglandin $F_{2 \alpha}$ to the ovarian artery following intrauterine administration in cattle. Biol. Reprod. 11, 543-552.

Horton, E.W. \& POYSER, N.L. (1973) Elongation of oestrous cycle in the guinea-pig following subcutaneous or intrauterine administration of indomethacin. Br.J. Pharmac. 49, 98-105.

Janson, P.O., Albrecht, I. \& AhrÉN, K. (1975) Effects of prostaglandin $F_{2 \mu}$ on ovarian blood flow and vascular resistance in the pseudopregnant rabbit. Acta. endocr., Copenh. 77, 337-350.

Jöchle, W., Tomlinson, R.V. \& Anderson, A.C. (1973) Prostaglandin effects on plasma progesterone levels in the pregnant and cycling dog (beagle). Prostaglandins 3, 209-217.

LeMaire, W.J., Yang, N.S.T., Behram, H.H. \&
Marsh, J.M. (1973) Preovulatory changes in the concentration of prostaglandins in rabbit graafian follicles. Prostaglandins 3, 367-376.

MCCAFFreY, T.V. \& MCCoOK, R.D. (1975) A thermal method for the determination of tissue blood flow. J. appl. Physiol. 39, 170-173.

MCCRACKEN, J. (1971) Prostaglandin $F_{2 x}$ and corpus luteum regression. Ann. N. Y. Acad. Sci. 180, 456472.

McCracken, J.A., Carlson, J.C., Glew, M.E., Goding, J.R., Baird, D.T., Green, K. \& SamuelsoN, B. (1972) Prostaglandin $F_{2 \alpha}$ identified as a luteolytic hormone in sheep. Nature, New Biol. 238, $129-134$.

Novy, M.J. \& Cook, M.J. (1973) Redistribution of blood flow by prostaglandin $F_{2 \alpha}$ in the rabbit ovary. Am. J. Obstet. Gynec. 117, 381-385.

Pharriss, B. (1971) Prostaglandin induction of luteolysis. Ann. N. Y. Acad. Sci. 180, 436-444.

STARK, E. \& VARGa, B. (1968) Effect of ACTH on target-organ blood flow with special reference to an extra-adrenal effect. Acta med. Acad. Sci. hung. 25, 367-381.

StaRk, E. \& VARGA, B. (1975) $\mathrm{PGE}_{2}$ as a possible mediator in the stimulatory effect of ACTH on ovarian blood flow. Acta med. Acad. Sci. hung. 32, 329-335.

STARK, E., VARGA, B. \& Ács, Zs. (1967) An extraadrenal effect of corticotrophin. J. Endocr. 37, 245252.

Received 18 October 1976 